\title{
Heterogeneity of atypical haemolytic uraemic syndromes
}

Thomas J Neuhaus, Seraina Calonder, Ernst P Leumann

\begin{abstract}
Atypical, non-diarrhoea associated haemolytic uraemic syndrome (D-HUS) is a heterogeneous disorder with a generally poor outcome, although this view has now been questioned. The clinical and laboratory features of 23 children with D-HUS, representing a third of all patients with HUS seen during the last 26 years, were examined. The median age was 4.9 years (range 3 days -13.8 years). Twenty one children ( $91 \%$ ) survived the initial phase. All patients except six infants aged $<18$ months required dialysis (74\%). Hypertension (43\%), cardiomyopathy $(43 \%)$, and cerebral convulsions $(48 \%)$ were common. Nineteen $(83 \%)$ children were followed up for a median period of 5.5 years (range $0.5-23.4)$. Only five $(26 \%)$ patients, among them four infants, recovered completely. Six (32\%) patients had one to 10 recurrences, including two siblings with neonatal onset, and eight $(42 \%)$ developed end stage renal failure. Five children underwent cadaveric renal transplantation, with recurrence and subsequent graft failure in two. Four children died, resulting in an overall mortality of $26 \%$. Atypical HUS is heterogeneous with regard to epidemiology, pathophysiology, and outcome. Children with a recurrent, familial, or neonatal course have worse outcomes; in contrast, infants not requiring dialysis in the acute phase have a better prognosis.

(Arch Dis Child 1997;76:518-521)
\end{abstract}

Keywords: haemolytic uraemic syndromes

Gasser et al first used the term 'haemolytic uraemic syndromes' (HUSs) in 1955. ${ }^{1}$ They reported five children from our institute with microangiopathic haemolytic anaemia, thrombocytopenia, and acute renal failure. Two of their patients had prodromal diarrhoea and two had pleuropneumonia; one patient had no prodrome. The plural form of HUS ('Syndrome' in German) was deliberately used in anticipation of the epidemiological, clinical, and pathophysiological heterogeneity of the disease. The current concept divides the HUSs into two major types: one is associated with a prodromal diarrhoea (D+HUS) and the other without diarrhoea (D-HUS). ${ }^{2-5}$

Most paediatric cases are D+HUS, affecting mostly younger children and generally having a good prognosis. ${ }^{3-13}$ D-HUS or atypical HUS is less common and is itself heterogeneous ${ }^{14}$ : some are familial, ${ }^{15}$ some are recurring, ${ }^{16}$ some have a neonatal onset, ${ }^{17}$ and some are related to neuraminidase producing microbes. ${ }^{18} \mathrm{D}$-HUS is generally associated with a greater morbidity and mortality than D+HUS..$^{3-10} 13$ So far, only two studies have been confined to D-HUS: one from London confirmed the worse outcome in D-HUS, ${ }^{19}$ whereas the other from Utah, USA, reported that children with D-HUS had a milder nephropathy and did not have poorer outcomes. ${ }^{20}$

Between 1970 and 1995 inclusive, 66 children with HUS were referred to our institute; $43(65 \%)$ had prodromal diarrhoea and $23(35 \%)$ did not. This paper reports the large clinical heterogeneity of patients with D-HUS, ranging from mild acute nephropathy with subsequent complete recovery to a familial, recurring course with neonatal onset and fatal outcome.

\section{Patients and methods}

The HUS was defined as the simultaneous and acute occurrence of microangiopathic haemolytic anaemia, thrombocytopenia, and renal failure. In children with D+HUS, verocytotoxin producing Escherichia coli (VTEC) have been examined in stool specimens since $1990^{21}$; eight of 20 samples were positive. Peritoneal dialysis or haemodialysis was performed in oliguric children unresponsive to diuretics or in the presence of severe electrolyte or acid-base disturbances. Plasma exchange, using the filtration technique, has been administered to all patients with D-HUS since 1992. The volume exchanged was $40 \mathrm{ml} / \mathrm{kg}$ body weight; a purified protein fraction was used and an infusion of fresh frozen plasma was given at the end of the treatment if plasma fibrinogen was $<1 \mathrm{~g} / \mathrm{l}$. Cardiomyopathy was defined as heart failure requiring the use of inotropes. A short course of immunosuppressive or cytotoxic drugs was given to two patients (azathioprine/ prednisone and vincristine, respectively). Histological examination of renal tissue was available during the acute phase in eight children.

Nineteen children with D-HUS were regularly followed up either by us or by the local paediatrician. Re-evaluation included any signs of clinical and laboratory evidence of recurrence, renal function (as assessed by plasma creatinine), blood pressure, ${ }^{22}$ and urine analysis (haematuria, normal $<10$ erythrocytes $/ \mu$; and proteinuria, normal $<1+$ on albustix and/or protein:creatinine ratio $<20 \mathrm{~g} / \mathrm{mol}$ ). Normal plasma creatinine $(\mu \mathrm{mol} / \mathrm{l})$ was defined according to age: $<40$ ( $\leqslant 4$ years), $<50$ ( $>4-6$ years), $<60$ ( $>6-10$ years), $<70$ ( $>10-12$ years), and $<90$ (>12 years). Complete recovery was 
Table 1 Clinical characteristics of 23 patients with D-HUS

\begin{tabular}{|c|c|c|c|c|c|c|c|c|}
\hline Age at presentation & $\begin{array}{l}\text { No of } \\
\text { patients }\end{array}$ & $\begin{array}{l}\text { Acute } \\
\text { dialysis }\end{array}$ & $\begin{array}{l}\text { Long term } \\
\text { follow up }\end{array}$ & $\begin{array}{l}\text { Complete } \\
\text { recovery }\end{array}$ & $\begin{array}{l}\text { ESRF* (initial } \\
\text { episode) }\end{array}$ & $\begin{array}{l}\text { Death (initial } \\
\text { episode) }\end{array}$ & Recurrence & Familial \\
\hline 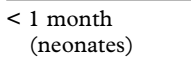 & 3 & 2 & 3 & 1 & $2(0)$ & $1(0)$ & 2 & 2 \\
\hline 1-18 months & 6 & 1 & 4 & 3 & 0 & 0 & 0 & 0 \\
\hline$>18$ months & 14 & 14 & 12 & 1 & $6(5)$ & $5(2)$ & 4 & 0 \\
\hline Overall & 23 & 17 & 19 & 5 & 8 & 6 & 6 & 2 \\
\hline
\end{tabular}

$\star \mathrm{ESRF}=$ end stage renal failure.

defined as the absence of recurrence and normal findings of plasma creatinine, blood pressure (without drugs), and urine analysis. Sequelae were defined as mild (normal plasma creatinine in the presence of hypertension or abnormal urine analysis, or both), moderate (increased plasma creatinine), or severe (end stage renal failure).

\section{STATISTICAL ANALYSIS}

Data between two groups were compared with the unpaired Student's $t$ test or Mann-Whitney test, where appropriate. Fisher's exact test was used to compare categoric variables.

\section{Results}

ACUTE PHASE ( $\leqslant 3$ MONTHS)

The median age of the 23 children with D-HUS (12 girls) was 4.9 years (range 3 days-13.8 years). All presented at admission with renal failure (median plasma creatinine $566 \mu \mathrm{mol} / \mathrm{l}$ ) and anaemia (packed cell volume $0.18) ; 22$ were thrombocytopenic $\left(46 \times 10^{9} / 1\right)$. The urine samples showed haematuria and proteinuria in 20 patients; three were anuric at admission. Twenty one of 23 children (91\%) survived the acute phase. Seventeen patients (74\%) were dialysed: 10 (including the two children who died) had temporary dialysis for 5-122 days (median 28 days) and seven (30\%) subsequently required long term dialysis. Six children, all infants aged $<18$ months, required no dialysis (table 1). Seven patients, all requiring dialysis, underwent plasma exchange: only one recovered completely; two had moderate sequelae and four developed end stage renal failure.

Ten children (43\%) were hypertensive. Cerebral convulsions occurred in $11(48 \%)$; six were also hypertensive and their median plasma sodium concentration was $132 \mathrm{mmol} / 1$ (range 119-144), which was slightly lower than in those without convulsions (median 135 $\mathrm{mmol} / \mathrm{l}$, not statistically significant). At discharge, 19 of the 21 surviving children had a normal neurological assessment, but two children with severe convulsions had developed spastic tetraparesis. Cardiomyopathy was present in $10(43 \%)$ children. One patient developed transient diabetes mellitus requiring insulin treatment for one week. Both children with an early fatal course had convulsions and cardiomyopathy.

Infections were present in 11 children (48\%). Neuraminidase producing Streptococcus pneumoniae was the causative organism in two (one with meningitis, one with pneumonia). A female neonate aged 12 days had HUS associated with (non-verocytotoxin producing) $E$ coli. Cultures of cerebrospinal fluid and blood were positive, whereas urine and stool cultures remained negative. Infections probably not related to the HUS were present in eight patients, upper respiratory tract infection in seven, and florid chickenpox in one.

\section{LONG TERM OUTCOME}

Nineteen $(91 \%)$ of the 21 surviving children were regularly followed up for a median period of 5.5 years (range $0.5-23.4$ ). Only two infants not requiring dialysis could not be located; at discharge their plasma creatinine had almost returned to normal. Five children (26\%) recovered completely, including three infants and one neonate who had not received acute dialysis. Of the eight children who had required acute dialysis, only one showed complete recovery, five had moderate sequelae (three were also hypertensive), and two boys died, one during the third episode of HUS and one of end stage renal failure six months after a $S$ pneumoniae meningitis.

End stage renal failure

Eight children (42\%) developed end stage renal failure, five after the initial attack and two siblings after a recurrent course. Of the seven children undergoing long term renal replacement treatment, two died, resulting in an overall mortality of $26 \%$ (six of 23 ; table 1 ). Five children had cadaveric renal transplantation.

\section{Recurrence}

Six $(32 \%)$ of the 19 children followed up had recurrent HUS, two of them after plasma exchange. Two brothers, born 1.9 years apart, had a neonatal onset with the first episode on the third and fourth day of life, respectively. The elder sibling required acute dialysis at the second to fourth attack and developed end stage renal failure after the fifth episode at the age of 6 months. During the next two years he had five further haematological episodes with anaemia and thrombocytopenia. $\mathrm{He}$ is currently 6 years old and is maintained on peritoneal dialysis. His younger brother required dialysis for end stage renal failure after the fourth episode at the age of 5 months. He had a further haematological episode within 8 months and died at 13 months of hyperkalaemia. Complement deficiency ${ }^{23}$ and methylmalonic acidaemia and homocystinuria (CBLC phenotype) ${ }^{24}$ were excluded.

Two further children had recurrences. One boy (aged 9.7 years) had three episodes within five months, requiring dialysis only during the fatal third episode. The other boy had two episodes within two months. During the inital 
Table 2 Published series of D-HUS, including present paper. Values are numbers of patients

\begin{tabular}{|c|c|c|c|c|c|c|c|}
\hline Reference & $\begin{array}{l}\operatorname{HUS}(D+ \\
\left.\text { and } D^{-}\right)\end{array}$ & $\begin{array}{l}D-H U S(\% \\
H U S)\end{array}$ & $E S R F^{\star}$ & Death & Recurrence & Familial & $\begin{array}{l}\text { Complete } \\
\text { recovery }\end{array}$ \\
\hline Milford et $a l^{6}$ & 288 & $15(5)$ & 4 & 3 & $?$ & 1 & $3 / 14 \dagger$ \\
\hline Loirat $e t a l^{8}$ & 161 & $14(9)$ & 6 & 1 & 6 & 3 & $0 / 13 \dagger$ \\
\hline Imoberdorf $e t a l^{9}$ & 42 & $7(17)$ & 2 & 2 & 1 & 2 & ? \\
\hline Tönshoff $e t a l^{10}$ & 89 & $21(24)$ & 1 & 10 & 3 & 3 & ? \\
\hline Kelles $e t a l^{11}$ & 95 & $12(13)$ & 1 & 2 & 0 & 0 & $3 / 10 \dagger$ \\
\hline Wende-Fischer et $a l^{13}$ & 61 & $13(21)$ & 6 & 4 & 7 & 0 & $?$ \\
\hline Fitzpatrick et $a l^{19}$ & 192 & $20(12)$ & 4 & 5 & 11 & 1 & $2 / 19+$ \\
\hline Siegler et $a l^{20}$ & 287 & $22(8)$ & 2 & 0 & 4 & 2 & $8 / 15 \dagger$ \\
\hline This paper & 66 & $23(35)$ & 8 & 6 & 6 & 2 & $5 / 19 \dagger$ \\
\hline Overall (\%) & 1281 & $147(11)$ & $34(23)$ & $33(22)$ & $38(26)$ & $14(10)$ & $21 / 90+(23)$ \\
\hline
\end{tabular}

$\star \mathrm{ESRF}=$ end stage renal failure.

$\dagger$ Number of patients followed up long term.

episode (aged 12 years) he had acute dialysis and plasma exchange for 10 days. During the second episode, requiring dialysis for two weeks, he began long term plasma exchange, with 53 exchanges during the next 15 months without any further recurrence.

Recurrence in the patients who had a transplantation occurred in two patients, resulting in immediate graft loss in a girl on day 1 and after four years in a boy. The girl is still maintained on haemodialysis, whereas the boy died three years later of heart failure. Neither of them had received cyclosporin.

Renal histology

All eight biopsy samples, taken in the acute phase, showed a thrombotic microangiopathy. Glomerular and arteriolar lesions were present in six patients: three developed end stage renal failure, including two brothers; two had moderate sequelae; and one (a neonate) recovered completely.

\section{COMPARISON WITH D+HUS}

All 43 cases of D+HUS were sporadic and there was no outbreak. The median age of D+HUS (19 girls) was significantly lower at 1.1 year (range $0.3-7.4, \mathrm{p}<0.005$ ). The initial clinical and laboratory presentation was not significantly different, however. Forty children (93\%) survived the acute phase and three died. Thirty one children ( $72 \%$ ) required acute dialysis. All patients were in renal failure (median plasma creatinine $382 \mu \mathrm{mol} / \mathrm{l}$ ) and were anaemic (packed cell volume 0.18); 39 were thrombocytopenic $\left(49 \times 10^{9} / 1\right)$ and 11 $(26 \%)$ were hypertensive. Sixteen $(37 \%)$ experienced cerebral convulsions, three suffered (fatal) cardiomyopathy $(7 \%, \mathrm{p}<0.002)$ and five $(12 \%)$ developed intussusception. Thirty four $(85 \%)$ of the surviving patients were followed up for a median period of 3.5 years (range $0.3-$ 13.9): $56 \%$ recovered completely, whereas 12 and $32 \%$, respectively, had mild and moderate sequelae. End stage renal failure, recurrence, or a HUS related death were not observed (all $\mathrm{p}<0.05)$. Nine of 10 children without dialysis made a complete recovery, in contrast with only 10 of 24 of the children who underwent dialysis.

\section{Discussion}

The current concept divides childhood HUS into postdiarrhoeal D+HUS and nondiarrhoeal or atypical D-HUS. $.^{2-5} \mathrm{D}+\mathrm{HUS}$ accounts for $>80 \%$ of paediatric cases, mostly infants and young children, ${ }^{3-13}$ and most cases of D+HUS are caused by VTEC. ${ }^{25} \mathrm{D}+\mathrm{HUS}$ is generally associated with a good prognosis. ${ }^{3-13}$ There remains, however, a considerable mortality of up to $10 \%$ during the acute phase and the risk of renal failure 15 years later after seemingly cured HUS is not negligible. ${ }^{26}$

Atypical HUSs, in contrast, comprise a heterogeneous group of various epidemiology, pathophysiology, and outcome. ${ }^{14} \mathrm{D}$-HUS is generally associated with a greater morbidity and mortality than D+HUS,,$^{3-1013} 19$ as it was in our series (table 2). Two publications have reported a similar outcome in D-HUS and D+HUS, however. ${ }^{11}{ }^{20}$ It is noteworthy that the patients from $\mathrm{Utah}^{20}$ had an unusually mild course during the acute phase, with only $21 \%$ requiring dialysis, which is far less than in the other series, ranging from 53 to $80 \% .{ }^{6-1013}{ }^{19} \mathrm{~A}$ full third of our patients with HUS had $\mathrm{D}$-HUS, which is higher than previously quoted, ${ }^{3-13} 1920$ except for an Italian study (34\% D-HUS). ${ }^{27}$ The absence of D+HUS outbreaks and epidemics in our referral area partly accounts for the high percentage of patients with D-HUS.

A subgroup in our series, seven infants aged $<18$ months with non-familial HUS, showed a remarkably good outcome: only one required acute dialysis and three of four with long term follow up recovered completely. The age at presentation and benign outcome mimicked the pattern of D+HUS associated with VTEC. VTEC was not routinely searched for in patients with D-HUS and only one child had a documented $E$ coli (non-verocytotoxin producing) infection. In fact, the Italian HUS study group has reported that $55 \%$ of children with D-HUS were positive for a VTEC infection and that VTEC positivity predicted a good outcome, independent of the presence of diarrhoea. ${ }^{27}$

Recurrence is common in D-HUS, in particular in association with familial and neonatal cases. ${ }^{81315161920}$ Familial occurrence accounts for approximately $10 \%$ of cases of D-HUS and the prognosis is often poor. ${ }^{810} 15$ Neonatal D-HUS represents a rare subgroup $^{81728-30}$ and its familial occurrence is associated with a worse outcome. ${ }^{828}$ Rare hereditary, autosomal recessive disorders, excluded in our patients, have been identified in a few families: hypocomplementaemia, ${ }^{20233132}$ methylmalonic aciduria, and homocystinuria 
due to intracellular vitamin B12 deficiency (CBLC phenotype), ${ }^{24}{ }^{33}{ }^{34}$ and collagen type III glomerulopathy. ${ }^{35}$ Recurrence has also been reported in 10 of 11 patients after an apparently successful plasma exchange treatment in the acute phase. ${ }^{19}$ Plasma exchange was less successful in our small series of seven patients. Four developed end stage renal failure and two had recurrences.

The risk of recurrence after transplantation in patients with D-HUS (and the role, if any, of cyclosporin) is still a matter of debate. The European Dialysis and Transport Association registry, including $\mathrm{D}+\mathrm{HUS}$ and $\mathrm{D}-\mathrm{HUS}$, quoted a recurrence rate of $10 \%$ in children ${ }^{36}$ and only one study showed a higher recurrence rate. ${ }^{37}$ No recurrence was reported in two publications on classical D+HUS. ${ }^{38}{ }^{39} \mathrm{~A}$ few series of sporadic recurrence of D-HUS after transplantation have been reported, however, ${ }^{13} 192039$ and patients with a recurrent course before transplantation may run a higher risk. ${ }^{19} 20$

A further distinct subgroup of patients with $\mathrm{D}-\mathrm{HUS}$ is associated with neuraminidase producing micro-organisms. ${ }^{18}$ The poor prognosis may be improved with prompt recognition and appropriate treatment. ${ }^{40}$

The renal biopsy sample findings in our small series were not conclusive with respect to their prognostic implications as arteriolar lesions were shown in children with both subsequent recovery and end stage renal failure. Extensive arteriolar involvement has been shown to be associated with D-HUS and an impaired outcome. ${ }^{3}$

We conclude that atypical or D-HUSs represent a heterogeneous group of various epidemiology, pathophysiology, and outcome. Children with D-HUS who require dialysis in the acute phase, and in particular children with a recurrent, familial, or neonatal course, have poorer outcomes. A subgroup of (young) patients presenting with a mild nephropathy and not requiring dialysis has a good prognosis, however.

1 Gasser C, Gautier E, Steck A, Siebenmann RE, Oechslin R. Hämolytisch-urämische Syndrome: Bilaterale Nierenrindennekrosen bei akuten erworbenen hämolytischen Anämien. Schweiz Med Wochenschr 1955;85:905-9.

2 Dolislager D, Tune B. The hemolytic-uremic syndrome. Spectrum of severity and significance of prodrome. $A m \mathcal{F}$ Dis Child 1978;132:55-8.

3 Habib R, Levy M, Gagnadoux MF, Broyer M. Prognosis of the hemolytic uremic syndrome in children. Adv Nephrol 1982;11:99-128.

4 Trompeter RS, Schwartz R, Chantler C, et al. Haemolyticuraemic syndrome: an analysis of prognostic features. Arch Dis Child 1983;58:101-5.

5 Kaplan BS, Proesmans W. The hemolytic uremic syndrome of childhood and its variants. Semin Hematol 1987;24:48 160.

6 Milford DV, Taylor CM, Guttridge B, Hall SM, Rowe B, Kleanthous H. Haemolytic uraemic syndromes in the British Isles 1985-88: association with verocytotoxin producing Escherichia coli. Part 1: clinical and epidemiological aspects. Arch Dis Child 1990;65:716-21.

7 Fitzpatrick MM, Shah V, Trompeter RS, Dillon MJ, Barratt TM. Long term renal outcome of childhood haemolytic uraemic syndrome. BMF 1991;303:489-92.

8 Loirat C, Baudouin V, Sonsino E, Mariani-Kurdjian P, Elion J. Hemolytic-uremic syndrome in the child. $A d v$ Nephrol 1993;22:141-68.

9 Imoberdorf G, Bianchetti MG, Rossi E, Gugler E, Oetliker $\mathrm{OH}$. Hämolytisch-urämisches Syndrom bei Kindern: Retrospektive über 19 Jahre. Schweiz Med Wochenschr 1993;123:1439-44.
10 Tönshoff B, Sammet A, Sanden I, Mehls O, Waldherr R, Schärer K. Outcome and prognostic determinants in the hemolytic uremic syndrome of children. Nephron 1994;68: 63-70.

11 Kelles A, Van Dyck M, Proesmans W. Childhood haemoytic uraemic syndrome: long-term outcome and prognostic features. Eur f Pediatr 1994;153:38-42.

12 Siegler RL, Pavia AT, Christofferson RD, Milligan MK. A 20 year population-based study of postdiarrheal hemolytic uremic syndrome in Utah. Pediatrics 1994:94:35-40.

13 Wende-Fischer R, Hoyer PF, Offner G, Brodehl J. Hämolytisch-urämisches Syndrom im Kindesalter. Monatsschr Kinderheilkd 1996;144:526-533.

14 Kaplan BS. Another step forward in our understanding of the hemolytic uremic syndromes: tying up some loose ends. Pediatr Nephrol 1995;9:30-2.

15 Kaplan BS, Chesney RW, Drummond KN. Hemolytic uremic syndrome in families. N Engl f Med 1975;292:1090-3.

6 Kaplan BS. Haemolytic uremic syndrome with recurrent episodes: an important subset. Clin Nephrol 1977;8:495-8.

17 Figueras J, Roldán A, Botet F, Palacín A, Jiménez R. Neonatal hemolytic-uremic syndrome. Clin Pediatr (Phila) 1995;34:220-2.

18 Seger R, Joller P, Baerlocher K, et al. Hemolytic uremic syndrome associated with neuraminidase-producing microorganisms: treatment by exchange transfusion. Helv Paediatr Acta 1980;35:359-67.

19 Fitzpatrick MM, Walters MDS, Trompeter RS, Dillon MJ, Barratt TM. Atypical (non-diarrhea-associated ) hemoytic-uremic syndrome in childhood. I Pediatr 1993;122: 532-7.

20 Siegler RL, Pavia AT, Hansen FL, Christofferson RD, Cook B. Atypical hemolytic-uremic syndrome: a comparison with postdiarrheal disease. F Pediatr 1996;128:505-11.

21 Burnens AP, Boss P, Orskov F, et al. Occurrence and phenotypic properties of verotoxin producing Escherichia coli in sporadic cases of gastroenteritis. Eur F Clin Microbiol Infect Dis 1992;11:631-4.

22 National Heart, Lung and Blood Institute Bethesda, Maryland. Report of the Second Task Force on Blood Pressure Control in Children. Pediatrics 1987;79:1-25.

23 Pichette V, Quérin S, Schürch W, Brun G, Lehner-Netsch G, Delâge JM. Familial hemolytic-uremic syndrome and homozygous factor H deficiency. Am $\mathcal{F}$ Kidney Dis 1994;24: 936-41.

24 Chenel C, Wood E, Gourrier E, Zittoun J, Casadevall I, Ogier H. Syndrome hémolytique et urémique néonatal, acidurie méthylmalonique et homocystinurie par déficit intracel

25 Karmali MA. Infection by verocytotoxin-producing Escherichia coli. Clin Microbiol Rev 1989;2:15-38.

26 Gagnadoux MF, Habib R, Gubler MC, Bacri JL, Broyer M. Long-term (15-25 years) outcome of childhood hemolyticuremic syndrome. Clin Nephrol 1996;46:39-41.

27 Gianviti A, Rosmini F, Caprioli A, et al. Haemolytic uraemic syndrome in childhood: surveillance and case-control studies in Italy. Pediatr Nephrol 1994;8:705-9.

28 Anthony PP, Kaplan AB. Fatal haemolytic-uraemic syndrome in two sibs. Arch Dis Child 1968;43:316-8.

29 Michalsen H, Andersen BD, Godal HC. The hemolytic uremic syndrome. Diagnosis and treatment with special reference to disseminated intravascular coagulation. F Oslo City Hosp 1975;125:117-23.

30 Rao SP, Sutton AL, Falter ML, Robinson MG. Chronic microangiopathic hemolytic anemia. NY State $f \mathrm{Med}$ 1979;79:1763-5.

31 Zachwieja J, Strzykala K, Golda W, Maciejewski J. Familial, recurrent haemolytic uraemic syndrome with hypocomplementaemia. Pediatr Nephrol 1992;6:221-2.

32 Carreras L, Romero R, Requesens C, et al. Familial hypocomplementemic hemolytic uremic syndrome with HLA-A3,B7 haplotype. $7 A M A 1981 ; 245: 602-4$.

33 Geraghty MT, Perlman EJ, Martin LS, et al. Cobalamin C defect associated with hemolytic-uremic syndrome. F Pediatr 1992;120:934-7.

34 Cerone R, Barbano G, Maritano L, et al. Syndrome hémolytique et urémique néonatal, acidurie méthylmalonique et homocystinurie par deficit intracellulaire de la vitamine B12. Arch Pédiatr 1994;1:762-3.

35 Gubler MC, Dommergues JP, Foulard M, et al. Collagen type III glomerulopathy: a new type of hereditary 7;354-60.

36 Mehls O, Rigden S, Ehrich JHH, Berthoux F, Jones EHP, Valderrábano F. Report on management of renal failure in Europe, XXV, 1994. The child-adult interface. Nephrol Dial Transplant 1996;11(suppl 1):22-36.

37 Hébert D, Kim EM, Sibley RK, Mauer MS. Posttransplantation outcome of patients with hemolytic-uremic syndrome: update. Pediatr Nephrol 1991;5:162-7.

8 Bassani CE, Ferraris J, Gianantonio CA, Ruiz S, Ramirez J. Renal transplantation in patients with classical haemolyticuraemic syndrome. Pediatr Nephrol 1991;5:607-11.

39 Gagnadoux MF, Habib R, Broyer M. Outcome of renal transplantation in 34 cases of childhood hemolytic-uremic syndrome and the role of cyclosporine. Transplant Proc 1994;26:269-70.

40 McGraw ME, Lendon M, Stevens RF, Postlethwaite RJ, Taylor CM. Haemolytic uraemic syndrome and the Thomson Friedenreich antigen. Pediatr Nephrol 1989;3:135-9. 